\title{
Industrial Parks as an Efficient Instrument for Sustainable Industrial Development of Region
}

\author{
Tatuev Arsen Azidovich
}

Kabardino -Balkarian State University named after Kh.M. Berbekov, 360004, Kabardino-Balkarian Republic Nalchik, Chernyshevskogo st., 173; E-mail: arsen.tatuev@mail.ru

\section{Doi:10.5901/mjss.2015.v6n6s2p360}

\section{Abstract}

\begin{abstract}
Contradictory difficulties of the Russian industrial development at the present stage demand the analysis of practical new organizational and economic forms. In this context relevance of research of a phenomenon of formation of industrial parks in the Russian economy increases. The research objective consists in the general assessment of efficiency of processes of formation of industrial parks in national reproduction taking into account dynamics of the general indicators. The implementation of the purpose of the research determines the formulation and solution of the following fundamental challenges: to identify the role of techno parks in the economic-organizational form of the industrial development; to consider the practical aspects of industrial parks development in the Russian economy; to analyze the current situation of the industrial parks in the Russian economy; to develop recommendations for industrial parks supporting. The main methods of the analysis were statistical groups and comparisons of data, including in dynamics, by criteria of property, associativity, certification, regionality, number of residents, the area, structure, quantity of the created workplaces, number of residents, etc.
\end{abstract}

Keywords: industry, industrial parks, branch structure, industrial policy

\section{Introduction}

The last decades with their social-economic transformation saw acceleration of post industrial production relations dissemination and economic knowledge generation, and signaled the time, when legal forms of strategic production development became a matter of particular importance. Plethora of recent studies has indicated the significantly increasing role of industry, though its share in employment and GDP production shrank. Industry, as a part of long technological chains, induces transition of a significant amount of interim gross value added to service sector of economy, what makes it a functional basis of postindustrial production (Gubanov, 2012; Rybakov, 2011; Inozemtsev, 1999). Moreover, only renovation of industry will allow achieving the transition to the sixth technological stage (Glazyev, 2010; Rybtsev, 2011). Implementation of such new functions requires introduction of new organizational and economic forms.

\section{Method}

The basis of the article were theoretical and methodological concepts and hypotheses, which are justified and presented in the modern economic literature that focus on the principles of the regional administration, geopolitics, economics of location, the theories of the regional growth and development, the development of industrial districts and clusters and works that reveal the methodological details of strategic management; the mechanisms of development and state support of the structural transformation of the economy; principles of the functioning of the industrial markets. The views of national and foreign economic representatives are observed with a critical eye in this work, and it is also used the advantages of the methodology in the different directions to study the structural changes in the economy.

During the implementation of goals and challenges are used subjective-objective, structural-functional, historical, logical, mathematical, and statistical research methods and tools of economic modelling that guarantees the validity and reliability of the results in the framework of the dialectical-synergetic positions from the side of the systemic approach.

The main methods of the analysis were statistical groups and comparisons of data, including in dynamics, by criteria of property, associativity, certification, regionality, number of residents, the area, structure, quantity of the created workplaces, number of residents, etc. 


\section{Literature Review}

For industrial growth Russian economy exploits both widely applied cluster approach and construction of industrial parks. The latter, as an organizational and economic form of industrial growth, proved to be very effective in the global economy (Maltseva \& Chevychelov, 2012), though in Russian economic environment the estimations are ambiguous.

From one side, according to experts opinion, former large and medium sized industrial enterprises, that closed when the demand for their product dropped, usually reorganize into industrial parks of different profiles. A good example of such reorganizations is transformation of so called industrial zone «Brick factory» (the Vsevolozhsky district of the Moscow region) into a modern and competitive automobile cluster (Demidov; 2010) according to global economic criteria. From the other side, there is an opposite opinion that implies that only few industrial parks from the whole number of those (more than 500 through the country), which have recently emerged, can be considered effective. Along with it, productivity of that small number of parks is disputable, if we take into consideration the amount of invested funds and provided administrative resources and the lack of up-to-dated innovative enterprises of full cycle, that produce unique, competitive and highly profitable products (Chernyshov, 2012).

In the whole, according to existing prevalent view among experts there is a need for accelerated development of industrial parks network with strong state support, especially at the stage of their launching (Stolyarova, 2012; Gribanov, 2014; Misharin, 2013). But it should be taken into account that there is not a unanimous opinion about the core of industrial parks concept (Astakhova, 2012; Plakhin, 2014; Belenov \& Smolyaninova \& Shurchkova, 2013).

Therefore, it seems reasonable to study practical aspects of industrial parks development in Russian economy.

\section{Results}

For example, Fig.1 shows summary data on industrial parks for the period of 2013-2014/ During this period industrial parks were being created rapidly. In 2013, it was announced that 50 new parks would be opened, with 25 to be launched in 2014.

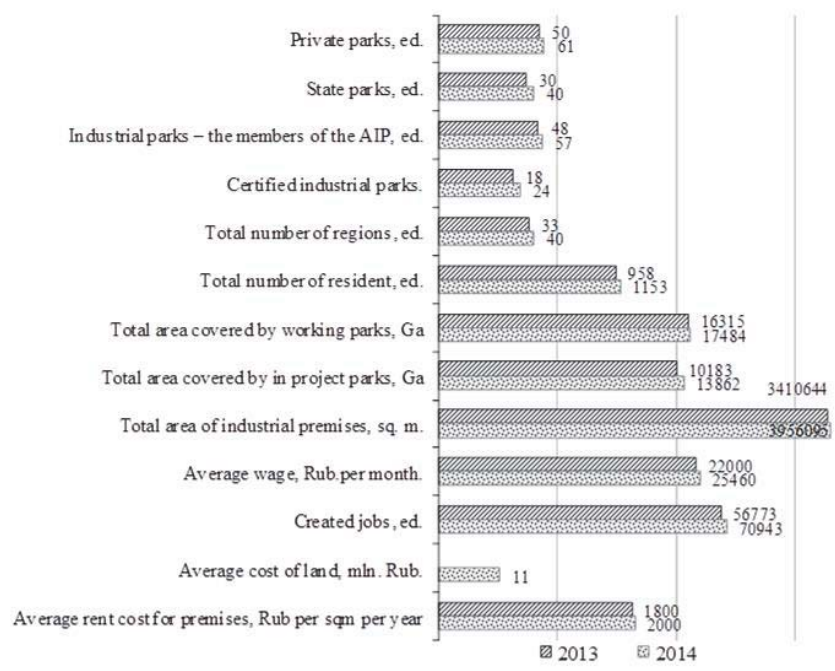

Figure 1. Summary date on industrial parks for the period 2014-2014 (the chart created by author, based on data presented in Industrial park in Russia Industry review.- M.: "Association of industrial parks", 2014.- page 8).

The year 2014 saw opening of industrial parks mostly in the regions that hadn't had similar industrial areas before. (Primorsky and Khabarovsky Kray; Dagestan, Kabardino-Balkaria, Karachay-Cherkessia, Tuva, Khakassia, Yakutia and Chechen Republics; Omsk, Orenburg, Sverdlovsk, Tomsk and Chelyabinsk areas). To sum it up, industrial parks were created on the land of 40 regions of the country (in 2013 - in 33 regions).

The total amount of industrial parks increased from 80 to 101. Among them 45 parks were working parks (36 - 
2013), and 56 - in the construction (44 - in 2013), 61 parks (50- in 2013) were in private ownership, 40 parks in state ownership (50 and 30 - in 2013 respectively). The total area of land spots for industrial parks construction increased to 31,3 hectares in comparison with 25,5 hectares in 2013. More than a half of total land spot area (17,5 hectares) was the area of working parks and 13,9 hectares related to parks in project. The total area of industrial premises amounted 3956, 1 thousand sq.m. Number of jobs increased from 56,7 thousands in 2013 to 70,1 thousands in 2014.

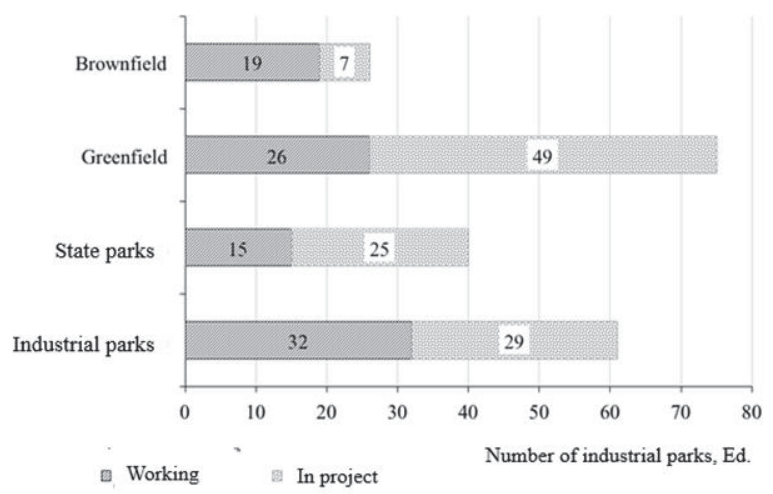

Figure 2. Structure of total amount of industrial parks of different types in 2014 (diagram created by author, based on data from in Industrial parks in Russia. Industry review.- M.: "Association of Industrial Parks", 2014.- page 13)

Figure 2 shows the structure of total amount of industrial parks of different types in 2014. The chart indicates that 32 from 61 private industrial parks were operating and 29 parks were in project. Also, 15 from 40 state owned industrial parks were operating, and 25 were in project. From 75 industrial parks of Greenfield type (for creation of this type of industrial parks residents were offered land spots with utilities supply designated for industrial construction and further exploitation of production facilities) only 26 parks were working, and remained 49 were in project. From 26 industrial parks of Brownfield type (resident were offered ready for use production facilities and infrastructure) 19 parks were working and 7 were in project.

On the whole, it can be stated that most of the industrial parks were parks in private ownership. Along with it, prevailing type of parks was Greenfield type (17). Moreover, we can see similar distribution among the parks types both in 2014 and 2013.

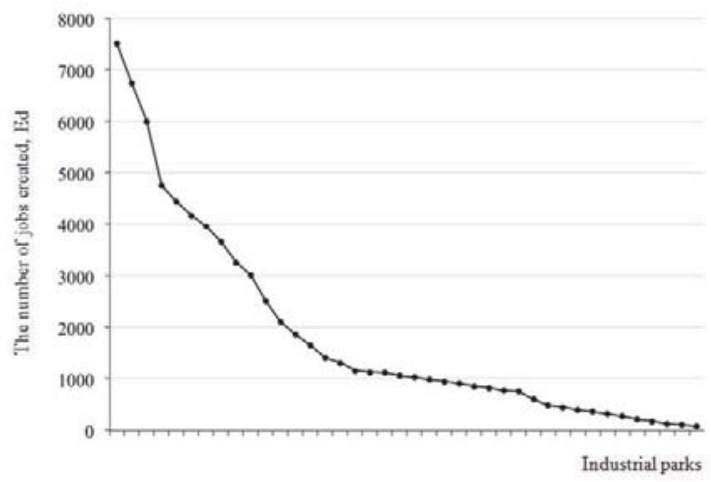

Figure 3. Number of jobs created in industrial parks in 2014, (the graph based on data from: Industrial parks of Russia: Industry review . - M.: NP "Association of Industrial Parks", 2014. - Page 17)

The great share of private parks in industry can be explained by investors desire to develop the most profitable and 
commercially attractive projects along with new business model application. At the same time experts from Association of industrial parks forecast growth of share of Brownfield type parks, brought about by strong interest to reconstruction of old industrial areas and in single -industry cities as well. $(18,19)$.

Figure 3 shows the graph with the number of jobs created in 2014. Thus, according to Association of industrial parks, the year of 2014 saw 41 industrial parks opened, with 71000 jobs created. For comparison, the number of jobs created in 2013 amounted 56000, 20 per cent less than in 2014. On average, each industrial parks employed 1730 workers in 2014. In 2013 this indicator was practically the same. One half of industrial parks employed about 1000 workers, when another half - from 1000 to 7500 workers. The employment was highest in such industrial parks as Grabtsevo" (7488 employees), "the Technopolis Himgrad" (6752 employees), "Degas Claster Noguinsc" (6000 employees).

According to experts from Association of industrial parks, development of industrial park field can foster generation of 250 jobs in nonproduction sectors in regions of industrial parks locations, if we admit that creation of a job in production sector leads to generation of 3 jobs in nonproduction sector.

An average wage of employees involved in production (except management staff) in industrial parks amounted 25,5 thousand rubles in 2014. However, the difference in wages can amount up to 100 per cent in different parks, depending of their location and average wage level in regions.

Figure 4 shows a graph with the number of residents of industrial parks in 2014. According to Association of industrial parks, 1153 enterprises were opened on the territory of industrial parks, among them 351 enterprises were opened in Greenfield type parks, and 802 companies - in Brownfield type parks.

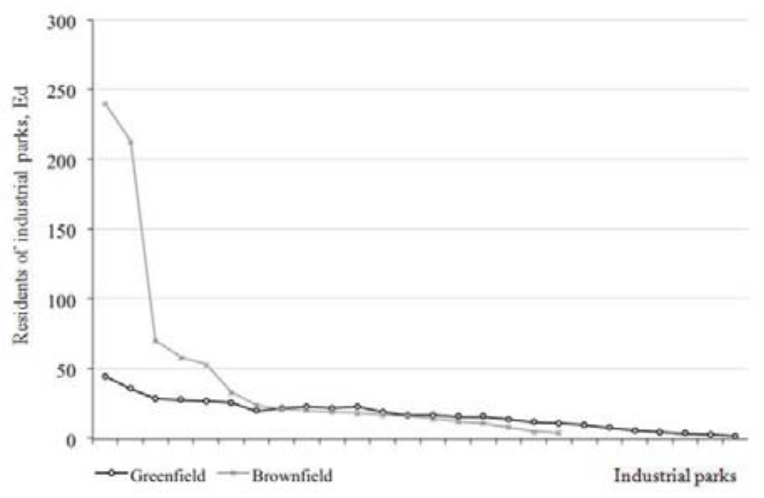

Figure 4. Number of residents of industrial parks in 2014, (the graph is created on the basis of data: Industrial parks of Russia: Industry review. - M.: NP "Association of Industrial Parks", 2014. - Page 19)

On the whole, the number of residents of industrial parks increased by 20 per cent in 2014, in comparison with 2013 (958 enterprises). Average number of residents varies depending on park type: it amounted 14 residents for Greenfield and 42 - for Brownfield. As the graph shows in most cases the number of residents in Greenfield and Brownfield parks is comparable except for 3 Brownfield of parks, ranging from 60 to 250 residents.

Leaders among the Brownfield parks in terms of the number of enterprises - residents are "KIP Master" and "Technopolis Himgrad", with residents number 238 and 210 companies, respectively. Leaders among the Greenfield parks in terms of the number of enterprises are "Alabuga" and "Vorsino", with the number of residents of 42 and 34 companies, respectively.

It should be noted, that Greenfield parks are more attractive for large production companies seeking for large land spots. As a rule, main residents of Greenfield parks are medium-sized and large companies with annual revenue from 500 million rubles. At the same time Brownfield parks are more attractive for small and medium business focused on the local market. The average number of employees in typical enterprises - residents of Brownfield parks amounts 20-30 people.

Figure 5 shows distribution of total amount of industrial parks in 2014 in federal districts of Russia. According to the chart slightly less than a half of the number of industrial parks were located on the territory of Central Federal District, belonging to four constituent entities: Moscow (15), Leningrad (12) and Kaluga (11) regions and the Republic of Tatarstan 
(8).

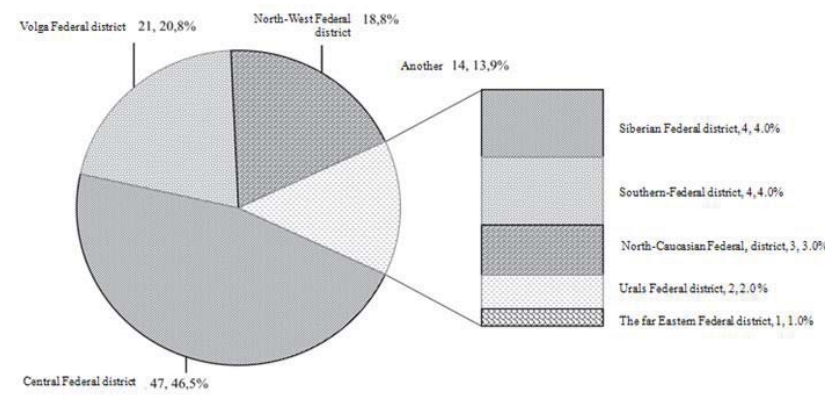

Figure 5. Distribution of total number of industrial parks in 2014 in federal districts of Russia, quantity in unit, shares in \% (the chart is created by the author on the basis of data: Industrial parks of Russia: Industry review. - M.: NP "Association of Industrial Parks", 2014. - Page 14)

In the other 36 regions from 40, where industrial parks were located, the number of production sites didn't exceed 3 in 2014. For instance, there were 21 industrial parks in the Volga Federal District - slightly more than $1 / 5$ from the total number of industrial parks in the whole coulntry. There were almost the same number of parks in the Northwest Federal Districtl -19 industrial parks, or $18,8 \%$ of their total number. And there were only 14 industrial parks $-13,9 \%$ of total number in the remained 5 federal districts.Among them 4 parks were located on the teriritory of the Siberian Federal District; 4 parks - in the Southern Federal District ; 3 - in the North Caucasus federal district; 2 - in the Ural federal district; 1 - in the Far East federal district.

Varying number of industrial parks from district to district over the territory of Russia, according to experts of Association of industrial parks, is a direct consequence of a trend towards development of industrial productions in an era of market transformations. It is connected with existing tendency to create industrial parks in zones of concentration of the processing productions. Accordingly, existing disbalance in the concentration of industrial parks in the whole country is a consequence of the pattern of economic division into districts and the corresponding trends towards social and economic development of certain regions. At the same time, development of industrial platforms outside the territory of the European part of the country is based on large-scale support from the state.

Figure 6. shows industry structure of industrial parks in 2012, disaggregated by the economic regions of Russia (according to Ernst \& Young company). Based on the chart, it is clear that 26 industrial parks from 66 ones, located in the Central economic region, are mono-sectoral parks, and the other 40 parks refer to multi-sectoral ones. From 14 industrial parks of the North Caucasus economic region only 1 park is mono-sectoral and 13 parks are multi-sectoral.

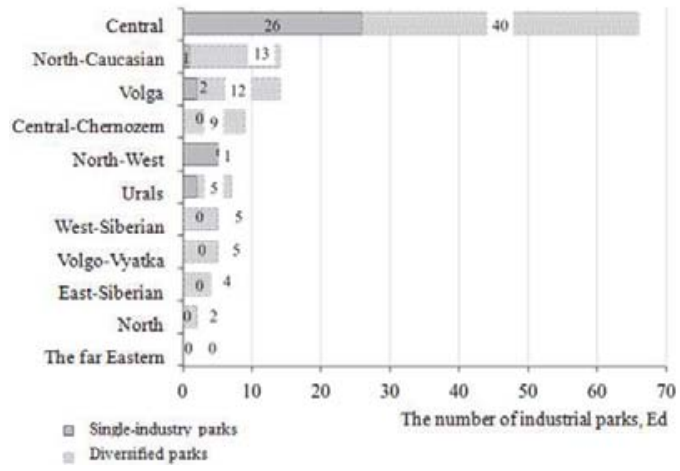

Figure 6. Branch structure of industrial parks in 2012 on the economic region of Russia (the chart is created by the author on the basis of data: Industrial parks of Russia//Ernst \& Young. - URL: http://www.ey.com/RU/ru/Industries/RealEstate/Industrial-parks---Overview) 
Two from 14 industrial parks located in the Volga economic region were mono-sectoral, and 14 ones were multi-sectoral. There were no multi-sectoral parks in the Central Black Earth economic region, and all 9 were among multi-sectoral parks. In the Northwest economic region 6 from 7 industrial parks were mono-sectoral treated 6, and only 1 was multisectoral. In the Uralsk economic region 2 from 7 industrial parks were mono-sectoral, and 5 ones were multi-sectoral. There were no mono-sectoral industrial parks industrial parks in the West Siberian economic region, and all 5 industrial parks were among multi-sectoral. There were no mono-sectoral industrial parks among 5 industrial parks in the VolgaVyatka economic region. They all were multi-sectoral. There were no mono-sectoral industrial parks in the East Siberian economic region, all 4 industrial parks were multi-sectoral. There were no mono-sectoral industrial parks in the Northern economic region, all industrial parks in this region were multi-sectoral. According to Ernst \& Young company there were no any industrial parks created in the Far East economic district in 2012.

On the whole, analysis of the chart allows us to conclude that multi-sectoral production sites predominate in this sector. For example, among 133 industrial parks (on the methodology of Ernst \& Young company) 96 (72,2\%) parks were multi-sectoral whereas remained $37(27,8 \%)$ were mono-sectoral parks, with 26 parks from this number located on the territory of the Central economic region.

\section{Discussion}

In turn, sectoral divergence of industrial parks doesn't permit us to use principles of ensuring concentration of production when some production programs are implemented. This feature discloses fundamental differences between industrial parks and innovative territorial clusters, that are created to achieve concentration of resources within a uniform production chain.

Nevertheless, despite fundamental differences between industrial parks and innovative territorial clusters, both forms of production organization generate specific infrastructure for consolidation of small, medium-sized and large enterprises, within realization of specific research and production chains to achieve desirable synergetic effects, that may ensure rise in economic efficiency and productivity of each enterprise or organization. But, if in case of industrial parks, such synergetic effects are provided mostly by advantages of using consolidated engendering infrastructures and facilities, with use of outsourcing services, especially in transport and logistic and municipal parts, industrial clusters additionally benefit from high level of concentration and cooperation when certain research and production chains are realized. In total both processes allow creating a new organizational production structure that ensure high level of competitiveness of productions which are carrying out the activity within it.

To support this process it seems reasonable to exploit all the opportunities presented through industrial policy for achieving integration and providing global industrial development. So, it is necessary to consider first a functional role of industry in development of innovative national economy and strengthening of economic security (Edelev \& Lyapuntsova, 2014; Tatuev \& Tatuev, 2015).

Mechanisms of industrial policy implementation should be developed through integration of actors of industrial development, with the state playing a key role. It is the state that through the public-private partnership approach can act as a direct agent, highly interested in development of high tech productions with key objective to manufacture high valueadded product of the six technological way.

\section{Conclusions}

Now the existing branch divergence of industrial parks doesn't allow to use effectively the principles of ensuring concentration of production within the solution of separate production tasks. Nevertheless, this form of the production organization forms the specific infrastructure serving for merger of the small, medium-sized and large enterprises within realization of concrete research and production chains for the purpose of achievement of the certain synergetic effects expressed in increase of economic efficiency and productivity of activity of each enterprise or organization.

Within industrial parks production efficiency increases by economy on use of the general production and engineering infrastructure, and also outsourcing services, especially in transport and logistic and municipal parts. For support of this process it is expedient to use possibilities of industrial policy regarding the public-private partnership mechanism when the state can act as the direct agent who is strategically focused on hi-tech productions with priorities of release of end products of advanced processing. 


\section{References}

Gubanov S. S. Majestic break. - M: Book world, 2012. - 224s.

Fishermen F.F. Promyshlennost as base of modernization of economy of Russia//Innovations. - 2011. - No. 6. - Page 27-30.

Foreigners of Century. New post-industrial wave in the West. - M.: Academia, 1999. - 640s.

Glazyev S.Yu. On a threshold of the sixth technological way//Sergey Glazyev. Official site. - URL: http://www .glazev.ru/econom_polit/ 233.

Rybtsev V. V. Transition to the sixth technological way as mechanism of transition to an innovative way of development//Creative economy. - 2011. - No. 4. - Page 3-8.

Maltseva A.A., Chevychelov V. N. World tendencies of development of technopark structures: selective analysis//Problem analysis and state and administrative design. - 2012. - No. 2. - T.5. - Page 29-42.

Demidov N. Stolypinskaya reform for the industry//the Expert. - URL: http://expert.ru/expert/2013/49/stolyipinskaya-reforma-dlyaindustriil.

Industrial parks, science and technology parks, industrial zones of St. Petersburg: state-of-the-art review of Credinform news agency. $\mathrm{SPb} ., 2012 .-70 \mathrm{~s}$.

Chernyshov S. Amin // Expert Siberia. - URL: http://expert .ru/siberia/2014/04/amin/.

Stolyarova E.I. Development of state business in Russia: industrial parks//Bulletin of the Russian university of friendship of the people. Series: Economy. - 2012. - No. 5. - Page 91-98.

Gribanov V. Promyshlennikov send to park/the Businessman, 2008. - No. 100. - URL: http://www .kommersant.ru/doc/903166.

Misharin M. L., Egorova Yu.M., Kovtun A.V. University innovative systems experience of an assessment of a state and directions of development/TVGU Bulletin. Economy and Management series. - 2013. - No. 33. - Page 38-52.

Astakhova A. Park industrial period//Direct investments. - 2012. - No. 9. - S.78-81.

Plakhin A.E. The principles of a clustering at creation of industrial parks in the Russian Federation//the Manager. - 2014. - No. 4(50). Page 72-78.

Belenov O. N., Smolyaninova T.Yu., Shurchkova Yu.V. Industrial parks: essence and main characteristics//Regional economy and management: electronic scientific magazine. - 2013. - No. 1(33). - Page 66-76.

Maltseva A.A., Goldfinches A.A. Terminologichesky the analysis of the concept "industrial park" from positions of modern science and practice//Innotsentr. - 2014. - No. 1(2). - Page 16-22.

More than a half of the declared projects of industrial parks are the Greenfield projects//the Official site of the consulting company "Knight Frank". - URL: http://www .knightfrank.ru/about/news/issue1748/.

Industry review. - M.: NP "Association of Industrial Parks", 2014. - Page 13-14.

Industrial parks of Russia//Ernst \& Young. - URL: http://www.ey.com/RU/ru/Industries/Real-Estate/Industrial-parks---Overview.

Edelev D. A., Lyapuntsova E.V. Innovative factors of social and economic development of the Russian industry/lthe Bulletin of the North Ossetian state university of Costa of Levanovich of Khetagurov. - 2014. - No. 4. - Page 250-255.

Tatuev A.A., Tatuev Ask. A. Factors of economic security in the industry and business activity in modern conditions//Economy and business. - 2015. - No. 6, p.1. - Page 900-903. 